\title{
A Clinical Survey Regarding Decision-Making for the Choice of Restorative Material in Endodontically Treated Teeth among Dentists
}

\author{
Dr. Abdulrahman Saad F Alasmari ${ }^{1}$, Dr. Muhammad Farhan Khan ${ }^{2}$, Dr. Ibrahim Yahya A Alsalhi, \\ Dr. Muhammad Waqar Hussain ${ }^{4}$, Hassan yahya A Alsalhi ${ }^{5}$
}

${ }^{1}$ Dental Intern, King Khalid University College of Dentistry, Post box 7506, Abha62528, Kingdome of Saudi Arabia

\begin{abstract}
Purpose: The objective of the study is to find out a more suitable restorative material for EET. To provide awareness among dentist regarding choice of restoring material and find out reason for the failure of restoration. Materials and Methods: The methodology of this study is a one page questionnaire which will be designed to investigate the awareness of Decision-making for the choice of restorations for endodontically treated teeth among dentists. The questionnaire will be including questions related to suitable restorative material for ETT. Results: Tooth colored composite was considered to be the material of choice among the dentists when more than half of the natural tooth structure remained after endodontic treatment. Tooth colored composite \& prefabricated post with tooth colored crown, both were equally preferred if less than $50 \%$ of the tooth structure was remaining. There was no statistically significant difference among the preferred restorative materials in both general dental surgeons and specialists. Majority of the dentist considered that post make effect on the esthetic outcome of the anterior teeth and they consider mechanical stresses while restoring anterior or posterior teeth with restorations. Composite was considered to be the material of choice among both the specialists and general dentists as well. Conclusion: Within the limitations of this study and the results following conclusions can be drawn. Composite is considered to be the material of choice among the general dentists and specialists as well. Despite the slight variations, there were no statistically significant differences found between the preference of materials used in the endodontically treated teeth between general dental surgeons and specialists.
\end{abstract}

Keywords: endodontically treated teeth, composite resins, Glass Ionomers , Resin modified GIC,Pre-fabricated \& custom made post and ferrule.

\section{Introduction}

The restoration of endodontically treated teeth which are mostly effected by caries, fracture or multiple restorations is an integral part of restorative dentistry ${ }^{1}$. The primary goal of endodontics followed by restoration is to restore normal function and esthetics as well ${ }^{2}$.Studies have proven thatthe major cause of endodontic failure is primarily not the endodontic failure itself but the restorative failure itself ${ }^{3}$. One of the major cause of restorative failure is endodontic failure due to micro leakage from the coronal restoration which causes an overall failure of the treatment ${ }^{4-5}$. The restorability of a particular tooth should be assessed before the start of endodontic treatment. There are multiple factors which should be kept in mind before initiation of the treatment and the formulation of a treatment plan such as position of the teeth in the arch, crown/root ration, mobility status, existing prostheses and the type of occlusal guidance $^{5-7}$. The restorative option varies according to the amount of remaining tooth structure and the disused contributing factors as well. It is very important to select which restoration is more suitable for a particular case. There is a variety of restorative materials available such as amalgams, composites, Glass Ionomers and Resin modified GIC which are mostly used directly ${ }^{6-8}$. The indirect restorative options could be Ceramics, Metal ceramics, cast gold alloys and base metal alloys which are fabricated in the dental laboratory and cemented ${ }^{9}$. Multiple techniques for the use of direct restorations have been claimed to prevent micro leakage underneath the restoration and to provide maximum strength to the overall restoration ${ }^{10}$. Pre-fabricated and custom made post are available for the restoration of ETT ${ }^{11-}$
12. The primary function of post is to hold the core material not to provide strength to the overall restoration. At least $2 \mathrm{~mm}$ of the ferrule is recommended for the overall success of the restoration and higher fracture resistance ${ }^{13}$.

The objective of the study is to find out a more suitable restorative material for EET. To provide awareness among dentist regarding choice of restoring material and find out reason for the failure of restoration. The methodology of this study is a one page questionnaire which will be designed to investigate the awareness of Decision-making for the choice of restorations for endodontically treated teeth among dentists. The questionnaire will be including questions related to suitable restorative material for ETT.

\section{Material and Methodology}

All dental practitioners at King Khalid University College of Dentistry were enrolled in this study. A pre-tested and validated self-administered questionnaire was used to investigate the awareness and practices regarding restorative materials in endodontically treated teeth. And Decisionmaking regarding restorations for endodontically treated teeth between dentists regarding of suitable restoration in ETT The questionnaire included questions relating to suitable restorative material in ETT. When there is more than or less than of half the tooth structure is remaining in posterior teeth and same thing in anterior teeth, is the dentist careful about mechanical stress while choosing restorative material for ETT, Which filling materials get more failure in ETT , the primary reason for restorative failures for ETT in endodontically treated teeth.

\section{Volume 6 Issue 12, December 2017}




\section{International Journal of Science and Research (IJSR) \\ ISSN (Online): 2319-7064}

Index Copernicus Value (2016): 79.57 | Impact Factor (2015): 6.391

Data will analyzed using SPSS version 20.0 software.

\section{Results}

A total of 121 dental practitioners were included in the study among which $101(83.5 \%)$ were general dental surgeons while the rest were specialist dental surgeons. General dental practitioners were in their first year of dental practice while specialist prosthodontists had atleast five years of experience after post-graduation.

Tooth colored composite was the preferred restorative material for endodontically treated tooth when more than $50 \%$ of the tooth structure is remaining among both general dental surgeons and specialists, however, tooth colored composite \&prefabricated post with tooth colored crown, both were equally preferred by specialists if less than $50 \%$ of the tooth structure was remaining. Tooth colored crown was the most preferred restorative material among general dental practitioners if $50 \%$ of the tooth structure was remaining
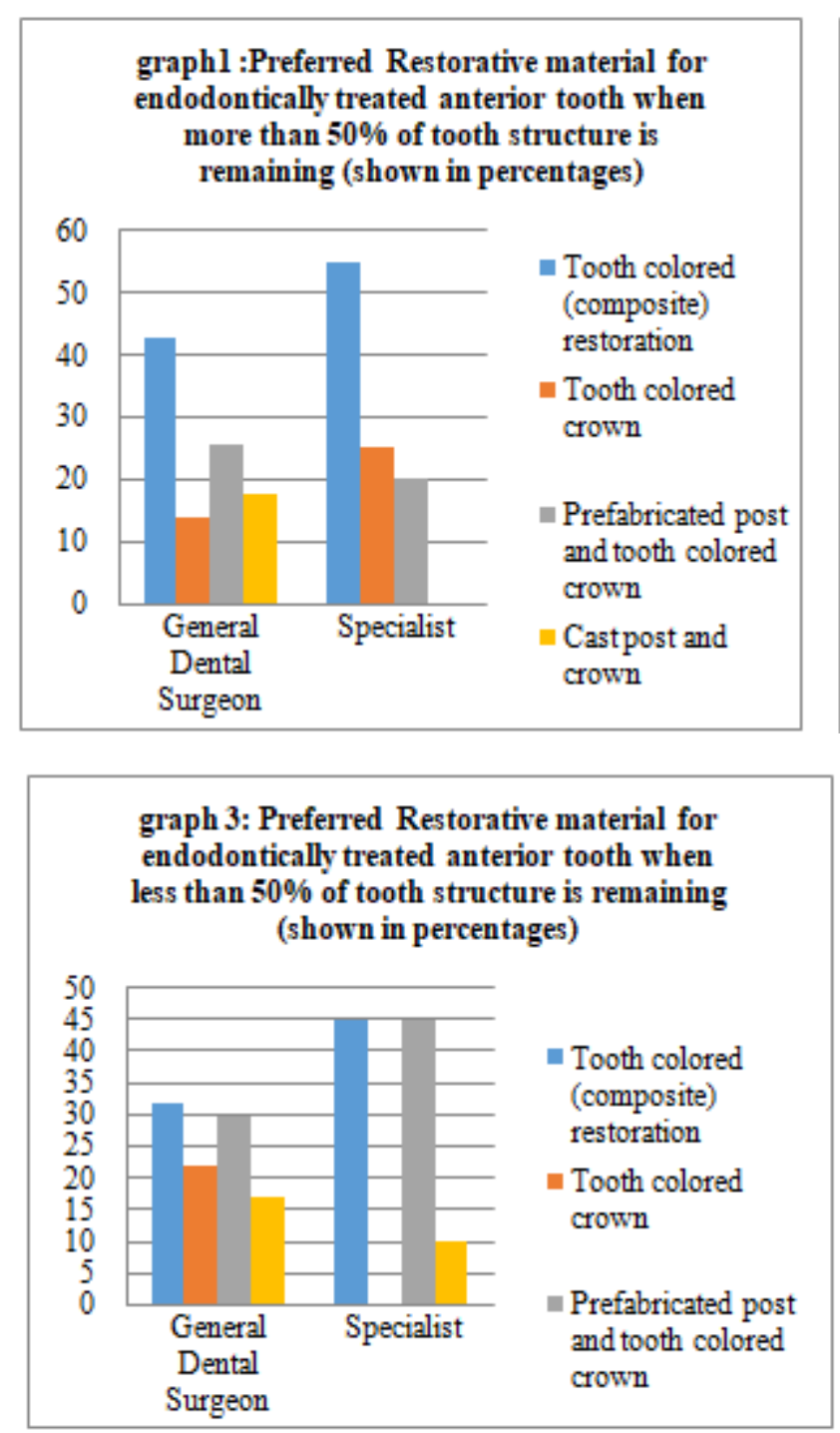

compared to prefabricated post with tooth colored crown being most preferred material among specialists. There was no statistically significant difference among the preferred restorative materials in both general dental surgeons and specialists.

Majority of general dental surgeons $(63.4 \%)$ and specialists $(40 \%)$ thought that post make effect on the esthetic outcome of anterior tooth depends on the remaining tooth structure. Furthermore, majority of general dental surgeons (71.3\%) and specialists $(75 \%)$ considered mechanical stress while considering the restoration of anterior tooth. Similarly, majority of general dental surgeons $(87 \%)$ and specialist $(85 \%)$ considered mechanical stress while restoration of posterior tooth. According to both general dental surgeons and specialists Composite was the preferred core material used in ETT while GIC was thought to associated with greater failure in ETT patients.

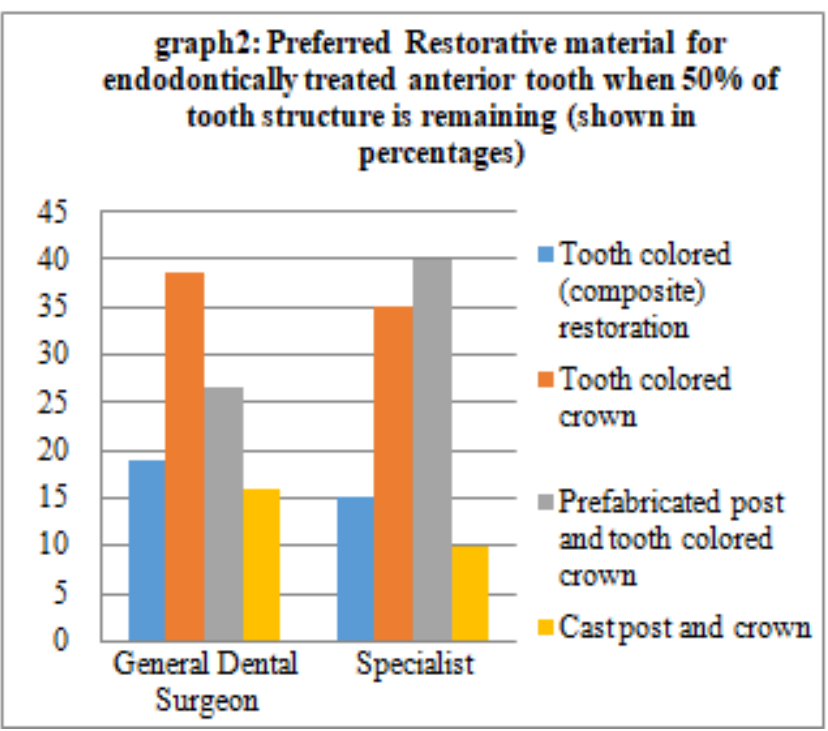

graph4: Do you think post make effect on the esthetic outcome of anterior tooth?

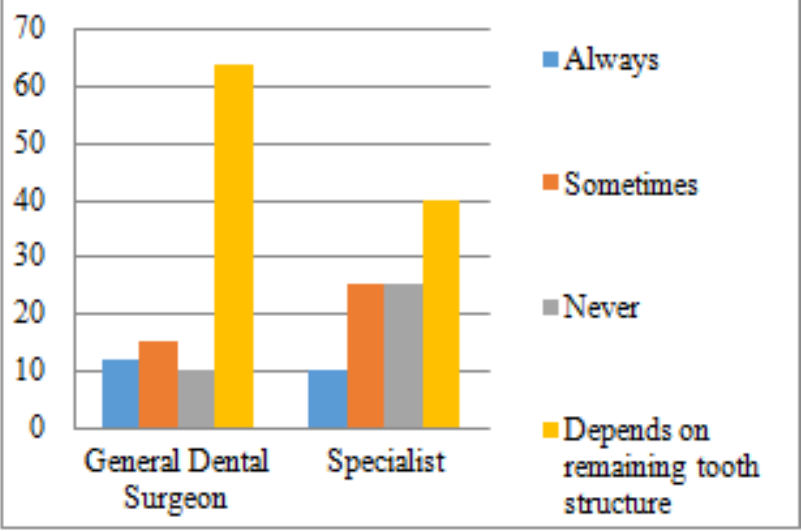


International Journal of Science and Research (IJSR)

ISSN (Online): 2319-7064

Index Copernicus Value (2016): 79.57 | Impact Factor (2015): 6.391
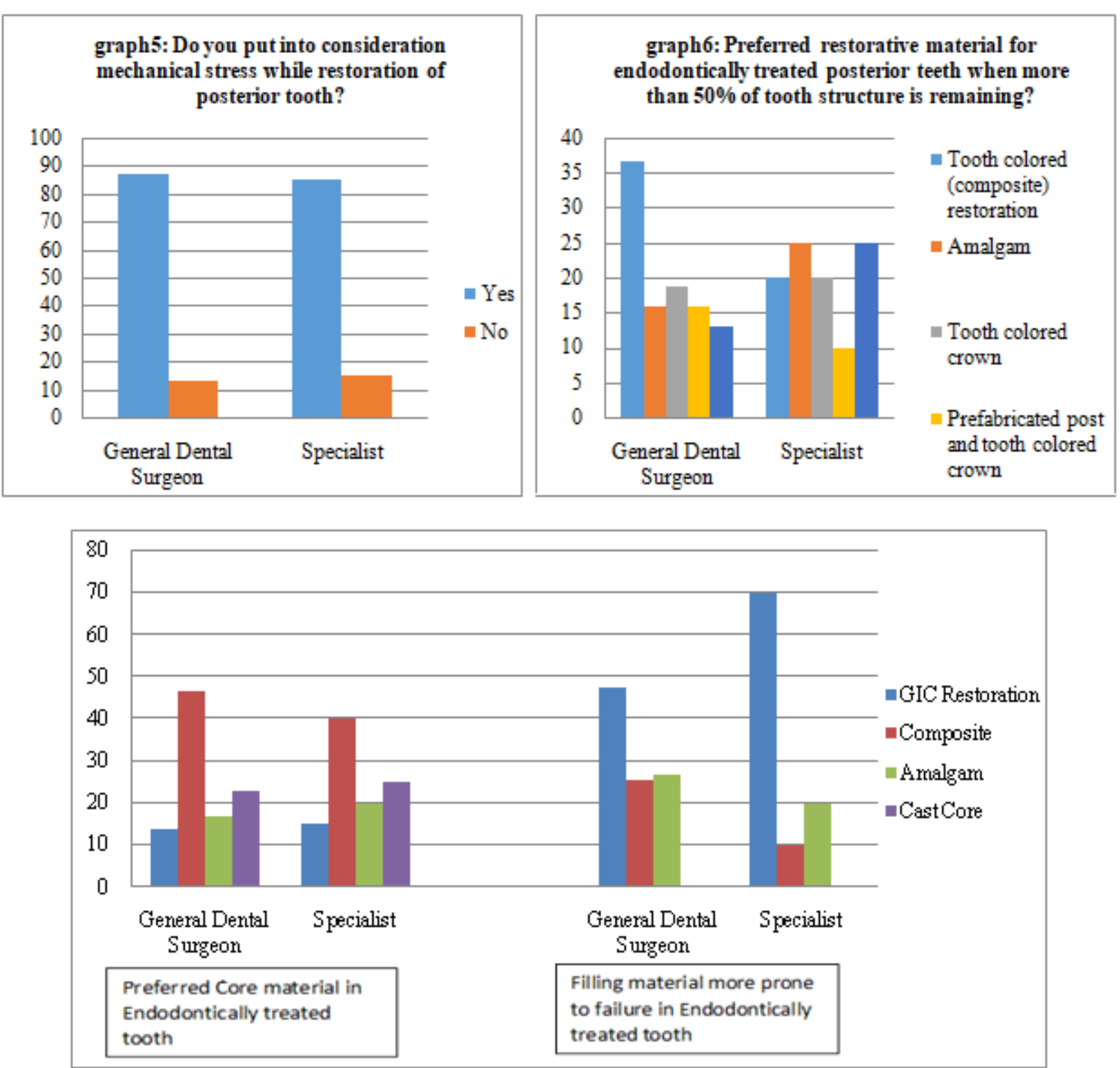

Graph 7

\section{Discussion}

The main purpose of the study was to find a most preferred restorative material for the restoration of anterior and posterior teeth in case when more than half of a tooth structure or less than half of tooth structure is remaining after endodontic treatment. Tooth colored Composite and tooth colored crown were preferredas the material of choice both by general dental surgeons and specialists as well without any significant variations. According to the results of the study considering the effect of post on esthetic outcomes its selection depends on the amount of remaining tooth structure after endodontic treatment. Mechanical stress should be taken under consideration when restoring both anterior and posterior endodontically treated teeth according to the results of the study.

Due to the endodontic treatment or previous carious lesion the endodontically treated tooth becomes week and prone to fracture as well ${ }^{1}$. There are multiple factors which should be kept in mind before proceeding towards the final restoration otherwise it could end up in a failure ${ }^{1-2}$. According to the previous studies it has been supported that when more than half of the tooth structure is present after ETT conservative line of treatment should be taken under consideration with GIC, Composite or resin composites ${ }^{1-3}$. When more than half of the tooth structure is lost after ETT tooth colored crown is the preference ${ }^{2-4}$. Post could be prefabricated or cast post but the prefabricated posts are widely used $\mathrm{u}^{5-6}$. The role of endodontic post is to retain the core material only ${ }^{7} .2 \mathrm{~mm}$ of ferrule is necessary for the tooth restoration with crown $^{7-}$ ${ }_{8,9,10}$. Mechanical stress should be taken under consideration while restoring ETT either anterior or posterior teeth ${ }^{10,11-12}$. This has been supported by the present study as well.

More studies should be conducted on a larger scale regarding the material preference and awareness of the contemporary composites, GIC, other revolutionary materials and the treatment options for the restoration choices.Their clinical implication should be taught in the under graduate and post graduate level so that a line could be drawn for the selection of the restorative material according to the clinical scenario and decision making could be done easily.

\section{Volume 6 Issue 12, December 2017}




\section{International Journal of Science and Research (IJSR) \\ ISSN (Online): 2319-7064}

Index Copernicus Value (2016): 79.57 | Impact Factor (2015): 6.391

\section{Conclusion}

Despite the slight variations, there were no statistically significant differences found between the preference of materials used in the endodontically treated teeth between general dental surgeons and specialists.

\section{References}

[1] Survey on restoration of endodontically treated anterior teeth: a questionnaire based study. Ratnakar P, Bhosgi R, Metta KK, Aggarwal K, Vinuta S, Singh N. J Int Oral Health. 2014 Nov-Dec;6(6):41-5.

[2] Int J Health Sci (Qassim). 2015 Jan;9(1):41-9. Knowledge, attitudes and practice of restoring endodontically treated teeth by dentists in north of saudiarabia. Akbar I1.

[3] $\mathrm{Br}$ Dent J. 2015 Jan;218(2):53-62. doi: 10.1038/sj.bdj.2015.27. Restoration of the root canal treated tooth. Eliyas S1, Jalili J2, Martin N3.

[4] Restoration of endodontically treated teeth. Mannocci F, Cowie J. Br Dent J. 2014 Mar;216(6):341-6. doi: 10.1038/sj.bdj.2014.198. Review.

[5] Prim Dent J. 2017 Feb 28;6(1):54-61. doi: NO DOI. Restoration of Endodontically-Treated Posterior Teeth. Shelley A.

[6] J Prosthodont Res. 2011 Apr;55(2):69-74. doi: 10.1016/j.jpor.2010.07.003. Epub 2010 Aug 14. Endodontically treated teeth: characteristics and considerations to restore them. Faria AC1, Rodrigues RC, de Almeida Antunes RP, de MattosMda G, Ribeiro RF.

[7] J Med Life. 2009 Apr-Jun;2(2):165-72. Current opinions concerning the restoration of endodontically treated teeth: basic principles. Vârlan C1, Dimitriu B, Vârlan V, Bodnar D, Suciu I.

[8] Cochrane Database Syst Rev. 2015 Sep 25;(9):CD009109. doi: 10.1002/14651858.CD009109.pub3. Single crowns versus conventional fillings for the restoration of rootfilled teeth. Sequeira-Byron P1, Fedorowicz Z, Carter B, Nasser M, Alrowaili EF.

[9] Prim Dent J. 2017 Feb 28;6(1):46-53. doi: NO_DOI. Restoration of Endodontically-Treated Anterior Teeth. Shelley A.

[10] Direct and indirect restorative materials. ADA Council on Scientific Affairs. J Am Dent Assoc. 2003 Apr;134(4):463-72. Review.

[11] Int J Prosthodont. 2001 May-Jun;14(3):245-9. Restoring endodontically treated teeth: a survey of current opinions among board-certified prosthodontists and general dental practitioners in Sweden. Eckerbom M1, Magnusson T.

[12] J Conserv Dent. 2014 Mar-Apr; 17(2): 183-187. The effect of ferrule presence and type of dowel on fracture resistance of endodontically treated teeth restored with metal-ceramic crowns. Vivek Aggarwal, Mamta Singla,1 Suman Yadav,1 Harish Yadav,2 Vikram Sharma, 1 and Saranjit Singh Bhasin3

[13] Adv Med. 2016;2016:5073459. doi: 10.1155/2016/5073459. Epub 2016 Jun 22. Impact of a Core Ferrule Design on Fracture Resistance of Teeth
Restored with Cast Post and Core. Shamseddine L1, Chaaban F2.

Volume 6 Issue 12, December 2017 